\title{
НЕОБХОДИМОСТЬ ИСПОЛЬЗОВАНИЯ НОВЫХ МЕДИА ПОДХОДОВ ДЛЯ ОРГАНИЗАЦИИ В СФЕРЕ ПРОДУКТОВОГО РИТЕЙЛА
}

\author{
А. С. Демин \\ Московский гуманитарный университет
}

Аннотация: В статье рассматриваются основные медиа подходы ключевых игроков в сфере продуктового ритейла. Рассмотрены медиа затраты, а также предложены новые варианты реализации коммуникации.

Ключевые слова: медиа; продуктовый ритейл; потребитель

\section{THE NECESSITY OF USING NEW MEDIA APPROACHES FOR ORGANIZATIONS IN THE FIELD OF FOOD RETAIL}

\author{
A. S. Demin \\ Moscow University for the Humanities
}

Abstract: The article discusses the main media approaches of key players in the field of food retail. Media costs are considered, and new options for implementing communication are proposed.

Keywords: media; food retail; consumer

На сегодняшний день реклама является одним из самых главных источников формирования успешности бизнеса. Выбор медиа каналов коммуникации для любой организации является одной из ключевых задач. Медиа каналы коммуникации могут состоять, как и из стандартных - национальное и региональное ТВ, радио, пресса, интернет, наружная реклама, так и нестандартных - видео-игры, специальные проекты, использование в своем продвижении блогеров (influencers), мобайл и многое другое.

Для продуктового ритейла характерно использование стандартного набора медиа, таких как: ТВ, радио и ООН (наружная реклама, Out of Home, далее $00 \mathrm{H})$. В последнее время ключевые участники рынка продуктового ритейла используют digital форматы, так как именно этот медиа канал 
позволяет более точно донести рекламное сообщение целевой аудитории посредствам обширных настроек таргетинга (Медиапланирование, 2019).

Проведем небольшой анализ основных игроков рынка продуктового ритейла. Сегодня самые крупные продуктовые ритейлы России занимают почти $30 \%$ всего рынка и продолжают прилагать гигантские усилия, чтобы увеличить этот показатель. К самым крупным игрокам российского рынка продуктовой розницы относятся:

— «X5 Retail Group». В кампанию входят такие бренды как: «Пятерочка», «Карусель» и «Перекресток». Кампания уверенно удерживает лидерство на рынке продуктового ритейла, ее долю оценивают примерно в 9,5\%;

— «Магнит». Сеть всячески старается навязать борьбу своему основному конкуренту — «Пятерочке» и старается удержать свою долю. Под маркой «Магнит» по России работает около 17 тысяч магазинов;

- «Ашан». Французский ритейлер активно осваивает российский рынок, открывая магазины разных форматов. Всего по России сейчас работает около 300 магазинов этой сети;

- «Лента». Отечественная сеть, развивающая форматы гипермаркетов и супермаркетов. В последние годы сеть показывает существенный прирост, и на сегодняшний день у нее работает 328 магазинов по всей стране;

- «Дикси». Сеть представлена магазинами под марками «Дикси» и «Виктория». Она охватывает в основном европейскую часть страны. Сегодня у данного продавца открыто 2700 магазинов;

- «Metro Cash\&Carry». Еще одна зарубежная сеть, активно интегрируется в российский рынок. Показатели последнего года у компании были не блестящими, но продавец старается удержать свою долю, развивая формат мелкооптового и розничного гипермаркета и магазина «у дома» «Фасоль». Всего у сети в России сейчас в активе примерно100 магазинов.

Также на этом рынке представлены такие сети, как «Окей групп», «Вкусвилл», «Азбука Вкуса», «Глобус», «Билла» которые активно демонстрируют свое желание увеличить долю. В целом объем рынка продуктового ритейла составляет около 25 триллионов рублей.

Практически все игроки на данном рынке используют в своем пакете медиа ТВ, радио и наружная реклама ООН. Их используют для того, чтобы наращивать охват целевой аудитории, так как данные медиа - самые подходящие для этой цели. На российском рынке продуктового устоялась идея, что если не использовать ТВ, ООН и радио в своем размещении, то это означает потеря конкурентоспособности. С одной стороны, так оно и есть, но с другой, нужно применять новые и оригинальные подходы донесения до покупателя рекламного сообщения, чтобы выделяться от конкурентов. 
Ниже представим график медиа инвестиций ключевых игроков продуктового ритейла за 2019 г., опираясь на данные Mediascope (www. mediascope.net):

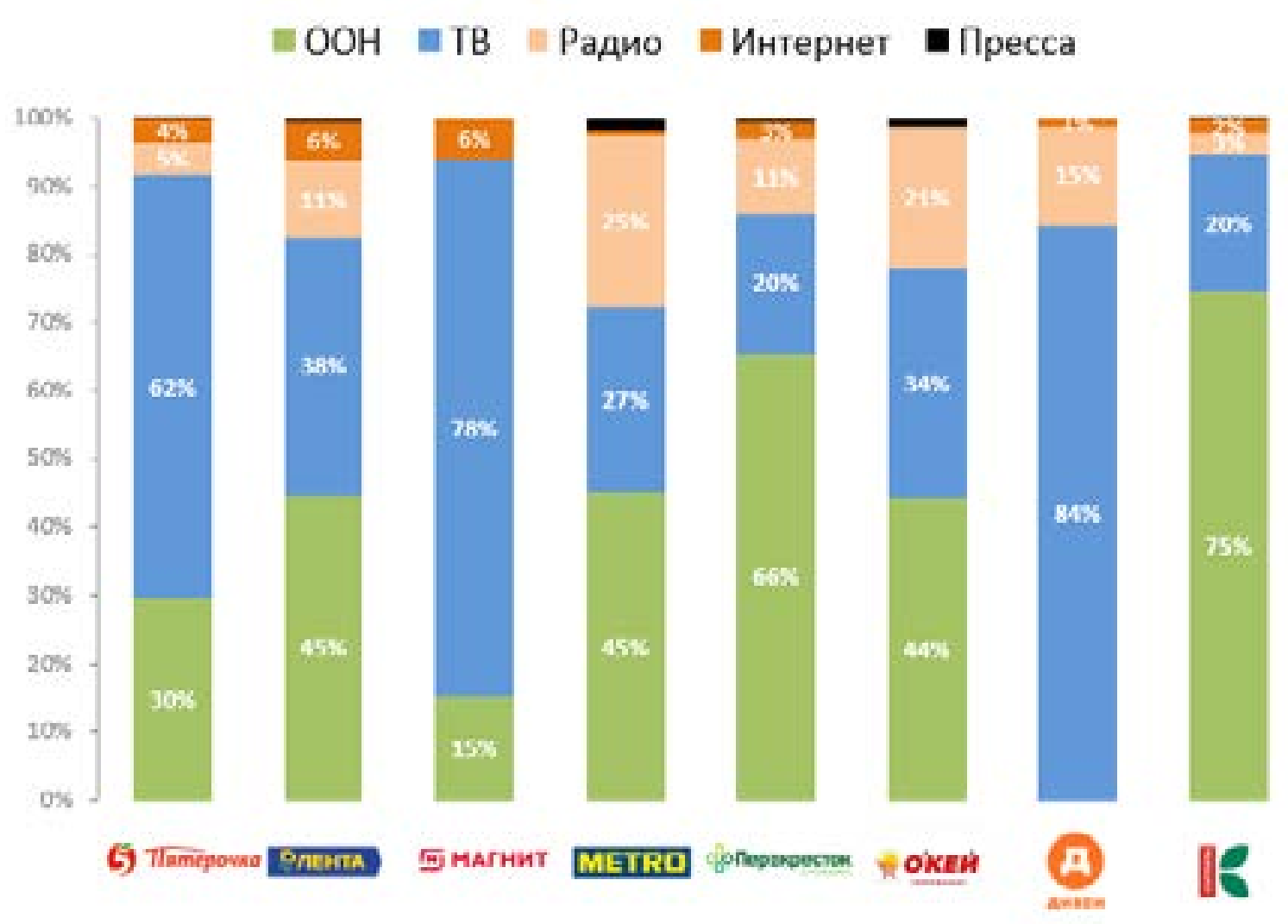

Рис. 1. График медиа инвестиций ключевых игроков продуктового ритейла за 2019 г.

Исходя из графика, можно сделать вывод, что основные драйверы роста инвестиций в медиа - это ТВ и ООН. Каждый игрок ставит перед собой задачу иметь наибольший SOV (доля голоса, Share of voice, далеe SOV) в определенном регионе или на всем рынке. Они составляют подавляющую часть медиа бюджета всех игроков. Эта тенденция сохраняется уже достаточно продолжительный период времени.

Тем не менее, рекламный рынок не стоит на месте. Каждый год появляются новые инструменты и варианты в различных формах медиа. Конечно же, Digital - это самое быстро развивающееся медиа и логично, что некоторые игроки продуктового ритейла постепенно начинают пробовать и тестировать размещение в нем.

Приведем статистику по объему Российского рынка Digital-рекламы. По прогнозам, в 2020 г. расходы на рекламу в России вырастут на 5,7\%, что выше темпов роста за предыдущий период (+4,4\% в 2019 г.). Ожидается, что 
в 2021 г. динамика рекламных инвестиций сохранится на прежнем уровне и составит $+5,6 \%$.

В 2020 г. цифровая реклама сохранит двузначные темпы роста $(+11,5 \%)$. Сегмент контекстной рекламы, который имеет самую высокую долю рынка digital (82\% в 2020 г.).

Онлайн-видео растет быстрее других каналов на российском рекламном рынке (+20\% в 2020 г.). Сегмент мобильного видео стремительно развивается, но ключевые форматы показывают разнонаправленную динамику: в первом полугодии 2019 г. mobile out-stream видеореклама выросла на 98\%, in-stream — на 10\%.

Мобильная экспансия российского рынка усиливается. В 2020 г. расходы на мобильную рекламу вырастут на 22,2\% до 133,3 млрд рублей и достигнут 50\% всех бюджетов на digital.

Интернет-реклама имеет гибкие инструменты таргетирования и централизованного управления маркетинговыми компаниями в разных системах контекстной рекламы. Также, именно Digital позволяет укрепить взаимоотношения с потребителем и сформировать лояльность.

Рассмотрим кейс «Пятерочки» и их недавней акции под название «Стиратели».

Фильмы Marvel удерживают внимание средств массовой информации. Фильм «Мстители: Финал» летом 2019 г. стал самым кассовым в истории кинематографа. Marvel обладает огромной аудиторией всех возрастов. Коллаборация «Пятерочки» с таким популярным брендом имела мощную эмоциональную основу, что позволило достичь большого охвата аудитории и превзойти плановые KPI (ключевой индикатор выполнения, Key Performance Indicator, далее KPI).

В прошлом году «Пятерочка» и компания Disney (которой принадлежит бренд Marvel) провели первую совместную акцию «Стиратели». Механика акции: при покупке товаров на определенную сумму, гости всех магазинов торговой сети получают подарок - в данном случае фигурку супергероя из вселенной Marvel.

Удалось добиться следующих результатов:

- В среднем каждый 10-й покупатель получал в подарок фигурку супергероя,

- Розничный товарооборот увеличился на 2,7\%,

- Рост среднего чека участников составил $12,5 \%$.

Поддержка акции осуществлялась по всем каналам коммуникаций как в офлайн, так и онлайн: непосредственно в магазинах, на ТВ, радио, в наружной рекламе, через спецпроекты во «ВКонтакте», FaceApp, Instagram, в 
Научные труды Московского гуманитарного университета 2020 № 1

«Яндекс.Навигаторе», в кинотеатрах и даже в школах (в Москве, Московской области и Санкт-Петербурге).

Центральным звеном в коммуникации стал лендинг (посадочная страница) - именно на нем размещалась актуальная информация и разнообразный тематический контент.

В результате на конец акции только в digital-канале удалось достигнуть охвата свыше 60,5 млн. Участники активно создавали собственный контент: за период акции в сети появилось более 500 созданных пользователями роликов с супергероями, а для конкурса на сайте участники прислали более тысячи работ-комиксов с изображениями своих семей.

Результаты акции показали, что аудитории «Пятерочки» интересны подобные проекты. Сами гости магазинов с большим позитивом восприняли акцию: активно обсуждали ее в социальных сетях, участвовали во всех тематических конкурсах.

Подобные кейсы проводили: «Перекресток» (Залипаки), «Дикси» (Прилипалы) и «Магнит» (Скрепыши).

Также, продуктовые ритейлеры активно используют инстурумент SuperGE0. Комбинация географического и поведенческого таргетинга позволяет получить сведения о фактической жизни потребителя. Такие геосоциальные сервисы, как AlterGeo или Foursquare, и некоторые приложения «Гугл» позволяют отследить перемещения человека и привязать их к определенным объектам на местности -например магазинам. Можно предлагать пользователям рекламу товаров, полностью соответствующих их интересам. Эти механизмы позволяют повысить эффективность локального таргетинга, превращая интернет-рекламу в элемент реальности.

В связи с ростом вовлеченности рекламодателей в influencer маркетинг - это одно из перспективных направлений для продуктового ритейла.

Инфлюенсер - человек, имеющий в медиа пространстве определенный вес. Этот человек мог стать известным до того, как появился в социальных сетях (например, Ольга Бузова или Амиран Сардаров), или же набрать популярность именно за счёт социальных сетей (Саша Спилберг и Wylsacom). И те, и другие считаются инфлюенсерами.

Работая с лидером мнений, бренд задействует сразу несколько маркетинговых механизмов:

Селебрити-эффект. Сегодня, блогеры популярнее телеведущих и попзвезд. При этом, многие ТВ каналы пришлашают их на свои передачи, чтобы повысить рейтинги. Работая с инфлюенсером, бренд получает в распоряжение авторитет и аудиторию известной личности; 
Выход на нужную аудиторию. Бренды выбирают инфлюенсеров не только по популярности, но и по тем каналам, которые те используют. Для продвижения продуктового ритейла можно не ограничиваться каким-то определенным каналом, но при этом нужно учитывать особенность каждого из них;

Нужная тональность. У каждого блогера - свой стиль, лексика, тональность, с которой он общается с подписчиками. Поэтому, например, через Instagram Сергея Шнурова часто продвигаются бренды крепкого алкоголя - тональность Сергея как нельзя лучше подходит для рекламы брутального «мужского» товара. Важно учитывать этот аспект при продвижении своего бренда, так как это может вызвать негативный эффект;

Доверительная коммуникация. Между блогерами и их подписчиками складываются доверительные отношения - благодаря возможности пообщаться со своим кумиром в социальных медиа напрямую: например, получить ответ на вопрос в комментариях. Мнению блогера будут доверять сильнее, чем мнению участнику шоу на ТВ канале;

Долгосрочное действие. Блогеры производят контент. Он остаётся в сети и продолжает набирать просмотры и комментарии даже спустя годы после публикации.

Продумать стратегию, интересную коммуникацию и эффективное использование данных медиа в сфере ритейла - даст существенное преимущество перед конкурентами и позволит нарастить как лояльность, так и продажи.

Также, стоит обратить внимание на социальные сети. Преимущества социальных сетей:

- Официальная страница сообщества создается бесплатно;

- Аудитория владеет привычным интерфейсом, а представители сооб-щества взаимодействуют с пользователями на безопасной и комфортной территории;

- Неограниченные возможности для проведения переговоров, общения, консультаций, заключения сделок напрямую с потенциальными клиентами;

- Возможность демонстрации своего товара или услуги путем обмена фотографиями, видео или постами о своей продукции;

- Одним из преимуществ SMM является его долговечность. Так как данный метод работает на перспективу, создавая образ и лояльное отношение к компании [(Современные маркетинговые ... , 2019).

Подводя итоги, можно сделать вывод, что в сфере продуктового ритейла, на данный момент, до сих пор преобладают стандартные медиа TB, Радио и ООН. Действительно, эти медиа каналы позволяют охватить 
достаточно большое кол-во человек и донести информацию в кратчайшее время. Поэтому ТВ, радио и ООН составляют колоссальную часть бюджета игроков на рынке продуктового ритейла. Но нельзя отрицать, что поле медиа с каждым годом расширяется и инструментов, чтобы достичь определенные цели становится больше. Ключевые игроки уже используют их в своем продвижении, ведь что-то новое может дать преимущество перед конкурентами и опередив их, успех будет гарантирован.

\section{СПИСОК ЛИТЕРАТУРЫ}

Современные маркетинговые коммуникации (2019) : монография / М. А. Симакина, О. М. Кожина: монография. М. : Издательство Московского гуманитарного университета. $160 \mathrm{c}$.

Медиапланирование (2019) : учеб. пособие: / О. И. Попова; М-во науки и образования Рос. Федерации, Урал. гос. экон. ун-т. Екатеринбург: [Изд-во Урал. гос.экон. ун-та]. 155 с.

Демин Алексей Сергеевич - магистрант 2 курса факультета экономики, управления и международных отношений Московского гуманитарного университета. Адрес: 111395, Россия, г. Москва, ул. Юности, д. 5 Тел.: +7 (916) 774-30-38. Эл. адрес: demin-1996@yandex.ru

Demin Alexey Sergeevich, Graduate Student, Faculty of Economics, Management and International Relations, Moscow University for the Humanities. Postal address: 5, Yunosti St., Moscow, Russian Federation, 111395 Tel.: +7 (906) 08725-10. E-mail: demin-1996@yandex.ru

\section{Для цитирования:}

Демин А. С. Необходимость использования новых медиа подходов для организации в сфере продуктового ритейла [Электронный ресурс]// Научные труды Московского гуманитарного университета. 2020 № 1. URL: http://journals.mosgu.ru/trudy/article/ view/1126 (дата обращения: дд.мм.гг.). DOI: 10.17805/trudy.2020.1.7 